\title{
Hormesis Effect of Methyl Triclosan (mTCS) on Cell Proliferation and Migration in Human Hepatocyte L02 Cells
}

\author{
Jing An ${ }^{1 *}$, Weiwei Yao ${ }^{1}$, Waner Tang ${ }^{1}$, Jingjing Jiang ${ }^{1}$, Yu Shang ${ }^{1^{*}}$ \\ ${ }^{1}$ Institute of Environmental Pollution and Health, School of Environmental and \\ Chemical Engineering, Shanghai University, Shanghai 200444, P. R. China
}




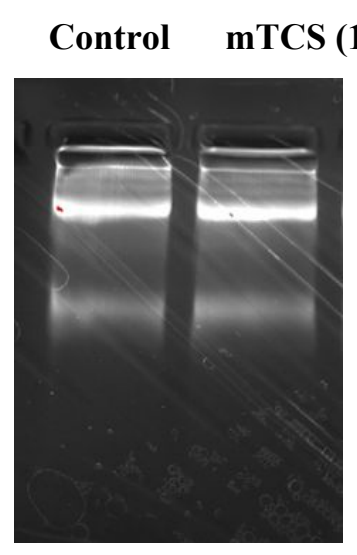

Figure S1. The agarose gel electrophoresis image of total RNA 